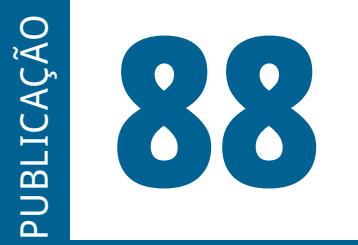

ISSN: 0101-9562

ISSN ELETRÔNICO: 2177-7055

SEQÜÊNCIA

Publicação do

Estudos jurídicos

e políticos

Programa de Pós-Graduação em Direito da UFSC

VOLUME 42 - ANO 2021 
SEQUÊNCIA - ESTUDOS JURÍDICOS E POLÍTICOS é uma publicação temática e de periodicidade quadrimestral, editada pelo Programa de Pós-Graduação Stricto Sensu em Direito da Universidade Federal de Santa Catarina - UFSC.

SEQUÊNCIA - ESTUDOS JURÍDICOS E POLÍTICOS is a thematic publication, printed every four months, edited by the Program in law of the Federal University of Santa Catarina - UFSC.

Versão eletrônica: http://www.periodicos.ufsc.br/index.php/sequencia

A publicação é indexada nas seguintes bases de dados e diretórios/

The Publication is indexed in the following databases and directories:

Base OJS

Base PKP

CCN (Catálogo Coletivo Nacional)

Dialnet

DOAJ (Directory of Open Access Journals)

EBSCOhost

Genamics Journalseek

ICAP (Indexação Compartilhada de Artigos de Periódicos)

Latindex

LivRe!

OJS
PKP
Portal de Periódicos UFSC
Portal do SEER
ProQuest
SciELO
Sherpa/Romeo
Sumarios.org
ULRICH'S
vLex

Ficha catalográfica

Seqüência: Estudos jurídicos e políticos. Universidade Federal de Santa Catarina.

Programa de Pós-Graduação em Direito. n.1 (janeiro 1980)-.

Florianópolis: Fundação José Boiteux. 1980-.

Publicação contínua

Resumo em português e inglês

Versão impressa ISSN 0101-9562

Versão on-line ISSN 2177-7055

1. Ciência jurídica. 2. Teoria política. 3. Filosoia do direito. 4. Periódicos.

I. Universidade Federal de Santa Catarina. Programa de Pós-graduação em

Direito

CDU 34(05)

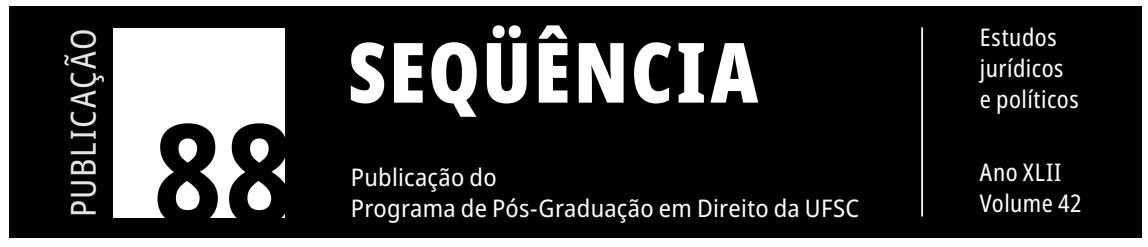




\title{
0 direito fundamental aos alimentos com base nas relações de padrastio e madrastio sob a perspectiva do princípio da solidariedade
}

\author{
The fundamental right to child support based on \\ the relationships of stepfather and stepmother from \\ the perspective of the principle of solidarity
}

Dóris Ghilardi

Universidade Federal de Santa Catarina, Florianópolis, Brasil

Daniela Braga Paiano

Universidade Estadual de Londrina, Londrina, Brasil

RESUMO: O presente estudo objetiva mostrar o cabimento de alimentos nas famílias reconstituídas. Destaca-se a relevância da investigação em razão do crescimento exponencial de segundas ou terceiras uniões com parceiros que possuem filhos de uma relação anterior. Tal cenário contribui para a discussão em torno do dever alimentar de padrastos ou pais socioafetivos para com seus enteados ou filhos afetivos, mormente quando assumido espontaneamente tal encargo durante o período de convívio. Inicialmente, o trabalho abordará o contexto atual das famílias, para então fazer as distinções necessárias entre os vínculos de parentesco e afinidade e as novas feições assumidas pela família. Conclui-se pela urgência de um olhar mais consentâneo com as demandas alimentares da contemporaneidade, de modo a assegurar o adequado cumprimento das funções familiares, da solidariedade entre seus membros e do superior interesse da criança e do adolescente. Utiliza como método o dedutivo, utilizando-se de levantamento bibliográfico, leis e julgados, bem como embasa em experiências estrangeiras na tentativa de buscar iluminar possíveis caminhos para o Direito brasileiro.

Palavras-chave: Alimentos - Famílias reconstituídas - Padrasto - Solidariedade. ABSTRACT: This study aims to show the possibility of child support in reconstituted families. It demonstrates the relevance of the study due to the exponential incre- 
ase in second or third marriages to partners who have children from a previous relationship. This scenario contributes to the discussion whether stepfathers/ stepmothers or socio-affective parents should pay child support to their stepchildren or affective children, especially when these responsibilities are taken spontaneously during the time they are living together. First, the article will highlight the current context of families and then make the necessary distinctions in parenting and the new characteristics that the family has taken on. It will conclude that there is an urgent need to pay more attention to today's requirements to ensure adequate fulfillment of family functions, solidarity among its members, and the best interests of children and adolescents. It uses the deductive method, using bibliographic research, laws and judgments, as well as based on foreign experiences in an attempt to shed light on possible ways for Brazilian Law.

KEYWORDS: Child Support - Reconstituted Families - Stepfather - Solidarity.

\section{INTRODUÇÃO}

Cada vez mais, é possível deparar-se com famílias mosaico, também chamadas de famílias recompostas, recombinadas, reconstituídas ou patchwork. Tais famílias são aquelas formadas entre pessoas em que um membro ou ambos tiveram relação precedente e que, normalmente, possuem filhos dessas uniões anteriores.

Esses arranjos familiares estão em sintonia com as diversas transformações ocorridas no Direito de Família e alinhados com os valores democráticos da Constituição da República Federativa do Brasil de 1988, responsável pela oxigenação e reconhecimento da igualdade e pluralidade familiar. Além disso, são também sintomáticos do aumento dos divórcios (no Brasil, por exemplo, um a cada três casamentos terminam em divórcio) e dissoluções de uniões estáveis.

Essa nova dinâmica familiar coloca em xeque o papel e as responsabilidades atribuídas pela lei exclusivamente aos pais, construída com base, unicamente, nas famílias tradicionais. Enquanto a titularidade desses poderes-deveres permanece legalmente como um atributo dos genitores, o seu exercício fático, não raramente, é assumido pelos padrastos e madrastas nas famílias mosaico. 
Diante dessas constatações, o presente estudo pretende investigar a temática abordada, guiando-se pela seguinte problematização: ao findar uma união reconstituída tem cabimento a obrigação alimentar do padrasto ou madrasta em favor do(a) enteado(a)?

Para tanto, o método de abordagem será o dedutivo, utilizando-se de levantamento bibliográfico, leis e julgados, além de se valer de experiências estrangeiras na tentativa de buscar iluminar possíveis caminhos para o Direito brasileiro. Em um primeiro momento o artigo mostra os novos horizontes do direito de família, na sequência, adentra na temática da parentalidade, para, finalmente, abordar os alimentos nas relações de padrastio e madrastio.

\section{NOVOS HORIZONTES DO DIREITO DE FAMÍLIA}

$\mathrm{Na}$ fase do positivismo jurídico, o Direito era considerado em sua neutralidade, segundo uma lógica simplista. O sistema era fechado e impermeável, acreditava-se em sua completude. A legalidade prevalecia em todos os padrões de justiça e legitimidade (GROSSI, 2007). Era nítido o predomínio das leis criadas pelo Estado que emolduraram alguns dos costumes até então vigentes, consagrando a tese da estabilidade.

O positivismo foi marcado por funções bem definidas, no qual o poder legislativo construía o Direito que, por sua vez, era interpretado pelo Judiciário, que não podia escapar da aplicação rigorosa da lei. "O dogma da completude, isto é, o princípio de que o ordenamento jurídico seja completo para fornecer ao juiz, em cada caso, uma solução sem recorrer à equidade, foi dominante" (BовBIO, 1999, p. 119).

Porém, "a noção de direito tecnicizada, esvaziada de conteúdo axiológico, voltado mais para a compreensão de que o direito só poder ser entendido como direito positivo (ius positum), e que o que está fora dele ou é invenção ou idealismo relativista" (BitTAR, 2014, p. 69) fez o movimento ser atingido por uma crise de legitimidade, sofrendo 
severas críticas. Isso ocorreu devido à inconsistência sistêmica diante da presença constante de fluxos ininterruptos de mudanças sociais, mudanças estas que traziam demandas inovadoras que não se encaixavam nas previsões legais (Melo, 1994, p. 71/76).

Surge, então, o fenômeno conhecido como pluralismo normativo, em que há duas alternativas: ou o positivismo mantém-se fiel ao princípio de que a segurança jurídica da sociedade necessita de uma ordem instituída, legitimando-se nas fontes sociais, ou mantém-se rígido, mas com desestabilizações constantes.

A inserção de valores e das aspirações sociais passa a ser levada em consideração, abarcando o Direito além das regras também os princípios, deslocando a legitimidade das normas à sua observância estritamente formal, para se preocupar com a legitimidade de seu conteúdo, de seus fins.

De acordo com Melo (1994, p. 75/76) durante o período do normativismo lógico, foi nas fontes tradicionais que o intérprete buscou inspiração e elementos teóricos para evitar o engessamento do Direito. Hoje, contudo, os obstáculos são muito mais complexos e desenham-se em representações e paradigmas nunca antes pensados.

Tanto que as dificuldades enfrentadas pelo Direito atualmente continuam sendo desafios. Segundo ponderações de Grossi (2007), apesar das mudanças ocorridas no campo jurídico, em que o olhar do jurista é mais desencantado, mais crítico às conquistas que a modernidade jurídica pretendia, e do mesmo estar aberto à realização e revisão de muitos dogmas construídos, é preciso com urgência recuperar a juridicidade para além do poder e do Estado, pois "O direito, pela sua tensão a encarnar-se, antes de ser poder, norma, sistema de categorias formais, é experiência, ou seja, uma dimensão da vida social" (Grossi, 2007, p. 57).

É fácil constatar que opção pelo pluralismo jurídico não é imune à reprovação. Ao mesmo tempo em que se abre aos valores, o Direito passa a estar sujeito às mais variadas formas de interpretação. A partir desse fenômeno, é acentuado o protagonismo do Judiciário, alvo de 
constantes críticas no tocante à hermenêutica utilizada que, grande parte das vezes, dá-se ao bel prazer do intérprete, em detrimento da observância da lei ou da concretização dos reais valores insertos no texto constitucional.

A busca do equilíbrio para o preenchimento das questões lacunosas trazidas pelas novas demandas representa um grande desafio, merecedor de maior atenção e rigor técnico, mormente no Direito de Família, o qual se depara com mutações constantes.

Tecidas tais considerações sobre a transição de fases no mundo jurídico, importa refletir ainda acerca do processo de fluidez presente na sociedade e que deixa para trás tradições e moldes para abrir espaço para novos formatos.

Para Bauman (2001), a era sólida foi substituída pela era líquida. Os líquidos, como lembra o autor, não suportam uma força tangencial quando imóveis e, por isso, sujeitam-se a mudanças constantes de forma quando submetidos a tal tensão. Diferente dos sólidos, que possuem forma definida, os líquidos fluem com facilidade, moldando-se aos espaços encontrados. Mas, em razão dessa característica, são volúveis e instáveis.

O "derretimento dos sólidos" é uma importante característica observada na sociedade: com os moldes sendo desmanchados, antigas e resistentes instituições deixam de existir ou passam a ter suas estruturas abaladas, fragilizadas. Aos poucos, as formas clássicas forjadas pelo poder cedem espaço para novas e sucessivas criações contemporâneas. Nas palavras de Bauman, (2001, p. 14) "Os poderes que liquefazem passaram do "sistema" para a "sociedade", da "política" para as "políticas da vida" - ou desceram do nível "macro" para o nível "micro" do convívio social.

A antiga modernidade cedeu lugar para a uma nova modernidade, aqui denominada de era contemporânea, onde não são fornecidas molduras pré-fabricadas e, as que ainda existem, mostram-se cambiantes, com grande poder de inovação e transformação.

Todos esses ensinamentos podem ser transportados com facilidade para o direito de família que, nas últimas décadas, passou por 
intensas transformações provocadas, principalmente, pela constitucionalização do direito, responsável pela ruptura da estrutura patriarcal, hierárquica e exclusivamente casamentária.

Com a oxigenação legal ocorrida após a edição da CFRB/1988, abriu-se espaço para novos formatos tanto de constituição de família quanto de vínculos de parentalidade. Se, outrora, a família sofria ingerência direta do Estado, com fortes influências da religião, atualmente consagra maior espaço à autonomia privada, prioriza o processo de afirmação de igualdade - gêneros, filhos e núcleos familiares - além de se encontrar em maior consonância com os horizontes emancipatórios, que buscam equilibrar os interesses entre o individual e o relacional.

Se, sob a égide do Código de 1916, eram tuteladas apenas as uniões casamentárias, marcadas pela indissolubilidade, hoje são também albergadas as uniões estáveis, bem como as famílias monoparentais e reconstituídas. Se outrora eram privilegiados somente os laços consanguíneos, hoje, também o são os socioafetivos (GHILARDI, 2015).

Tudo isso, ao menos, no discurso jurídico, já que, na prática, não é difícil encontrar resquícios do modelo antigo. Até porque nenhuma forma de convívio humano é passível de ser plenamente substituída, nem de ser totalmente reestruturada. Ao Direito é basicamente impossível prever todas as futuras demandas inerentes aos laços humanos. Tanto que, se na família casamentária estavam bem demarcadas as atuações e papéis tanto do pai quanto da mãe, o que dizer dos papéis e atribuições desempenhados nas famílias mosaico pelos personagens do padrasto e madrasta?

Logo, a releitura e novas compreensões da estrutura familiar contemporânea têm colocado em pauta diversas questões, entre elas, a manutenção da obrigação alimentar em seus modelos clássicos. Nesse contexto, observa-se que a norma jurídica brasileira foi estruturada com base na família nuclear tradicional, não dando conta da complexidade inerente às entidades familiares atuais, que requer a construção de soluções adequadas e equalizadas com os valores constitucionais. 


\section{PARENTALIDADE: ANÁLISE DAS RELAÇÕES DE PARENTESCO, FILIAÇÃO E SUA PERSPECTIVA ATUAL}

O Direito ordena a relação interna dos membros da família por meio do parentesco, que está essencialmente relacionada à filiação (FACHin, 1992, p. 19). O laço jurídico que une pais e filhos será aqui tratado como vínculo de parentalidade. Esse vínculo pode ser decorrente de diferentes origens, implicando em efeitos jurídicos distintos.

O Código Civil (2002), em seu art. 1.593, prevê que o "parentesco é natural ou civil, conforme resulte de consanguinidade ou outra origem”. Ou seja, a primeira forma prevista no Código, é o parentesco biológico, consanguíneo e a segunda é o parentesco de outra origem (que não a biológica), abrangendo os vínculos resultantes de adoção, da posse de estado de filho, algumas técnicas de reprodução assistida, podendo esses exemplos de filiação civil ser denominados de filiação socioafetiva.

É importante destacar que, em casos que envolvam a multiparentalidade, essa forma de parentesco prevista no código não é excludente como mencionada no art. 1593, de modo que o parentesco será natural e civil, quando decorrente de múltiplos vínculos parentais (Paiano, 2016, p. 213).

Parentesco e filiação estão intimamente ligados, de modo que “(...) o vínculo jurídico da filiação, liga uma pessoa a seus pais, numa relação paterno-filial, harmonicamente corresponde a uma relação materno-filial" (FACHin, 1992, p. 20).

O vínculo decorre tanto dos laços biológico como do socioafetivo, entre ascendente, descendentes e colaterais até quarto grau. Assim, afirmam Cristiano Chaves de Farias e Nelson Rosenvald que o estudo do parentesco diz respeito “(...) às relações estabelecidas entre pessoas que integram uma comunidade familiar”, ou ainda, “(...) o vínculo, com diferentes origens, que atrela determinadas pessoas, implicando em efeitos jurídicos diversos entre as partes envolvidas" (Faria; Rosenvald, 2021, p. 569). 
Cabe ressaltar que, uma vez estabelecida a filiação e, consequentemente, o parentesco, efeitos decorrerão dessa relação jurídica, sejam eles patrimoniais, como alimentos e sucessórios, quanto extrapatrimoniais, como direito ao nome, filiação, parentesco, guarda e visita (Paiano, 2016, p. 207).

Explica Heló́sa Helena Barboza (2013, p. 118) que o parentesco tem origem na filiação, já que para determinar a linha ou o grau do parentesco, tem-se como referência a relação de ascendência e descendência, ou seja, a filiação e daqui decorrem seus efeitos jurídicos. No mesmo sentido afirma Scalquette (2020, p. 127) que filiação é “a relação de parentesco em linha reta de primeiro grau que se estabelece entre pais e filhos, seja essa relação decorrente de vínculo sanguíneo ou de outra origem legal (...)."

Diferentemente do parentesco, que traz efeitos jurídicos do seu estabelecimento, encontra-se a possibilidade de se conhecer a origem genética ou ancestralidade, prevista no art. 48 do Estatuto da Criança e do Adolescente. Esse artigo possibilita ao adotado ter acesso aos autos e saber quem são seus genitores biológicos. Contudo, tal possibilidade não estabelece vínculos parentais - que foram rompidos por meio da desconstituição do poder familiar a fim de que a criança/adolescente fosse colocada para adoção, salvo os impedimentos matrimoniais.

O parentesco forma-se na linha reta ascendente e descendente (art. 1591) e na linha colateral ou transversal até o quarto grau (art. 1592) - esses são provenientes de um só tronco, sem descenderem uns dos outros. A relevância de se saber qual o grau de parentesco existe entre os membros de uma família, conforme já dito, são os efeitos que dela decorrem - recebimento de herança, pagamento de alimentos, impedimento matrimonial.

Explicam Tepedino e Teixeira (2020, p. 199) que o tema parentesco acompanha as discussões concernentes às mudanças nas famílias, e as influências trazidas pela biotecnologia têm surtido efeito na estrutura do parentesco, assim, "novas situações reclamam o reconhecimento 
parental, a fim de que determinadas pessoas pertençam, juridicamente, a uma mesma comunidade familiar."

Além do parentesco propriamente dito, há também os vínculos dos parentes afins ou vínculos de afinidade, oriundos das relações de conjugalidade, previsto no art. 1.595 do CC: "Cada cônjuge ou companheiro é aliado aos parentes do outro pelos vínculos de afinidade".

No que se refere à afinidade, pode-se perceber uma incongruência no Código. O art. 1595, em seu caput menciona vínculo de afinidade, enquanto em seu parágrafo único, o Código fala em 'parentesco por afinidade' - limitando-se aos ascendentes, descendentes e irmãos. Sobre isso, explica Gavião (2010, p. 532) que a "afinidade nunca foi, entre nós, parentesco. O Código anterior qualificava essa relação jurídica simplesmente de vínculo, cujos efeitos se limitavam a impedir, entre os afins, o casamento."

O Código Civil Português, em seu art. 1584, explica que "Afinidade é o vínculo que liga cada um dos cônjuges aos parentes do outro". “Trata-se, pois, de uma relação de família que não deve confundir-se com a de parentesco, baseada em laços de sangue. Uma coisa são os parentes e outra os afins" (CostA, 2013, p. 279).

Se a afinidade fosse vínculo de parentesco, geraria os efeitos aqui já mencionados e sobre um desses efeitos, no que se refere ao recebimento de herança por nora/genro. Já decidiu o Tribunal de Justiça de São Paulo (2021) ${ }^{1}$, recentemente que "Na linha transversal, somente se dá o direito de representação em favor dos filhos de irmãos

\footnotetext{
Agravo de instrumento. Inventário. Pedido da agravante de habilitação no inventário da irmã do falecido cônjuge. Indeferimento. Insurgência recursal. Não acolhimento. Artigo 1853 do Código Civil. Na linha transversal, somente se dá o direito de representação em favor dos filhos de irmãos do falecido, quando com irmãos deste concorrerem. Ilegitimidade da cônjuge sobrevivente para representar o cônjuge pré-morto em direito sucessório, ficando esse direito aos seus descendentes, sobrinhos da falecida. Recurso desprovido. (TJSP; Agravo de Instrumento 210627337.2021.8.26.0000; Relator (a): Silvério da Silva; Órgão Julgador: $8^{\text {a }}$ Câmara de Direito Privado; Foro Regional XI - Pinheiros - $2^{\text {a }}$ Vara da Família e Sucessões; Data do Julgamento: 16/06/2021).
} 
do falecido, quando com irmãos deste concorrerem. Ilegitimidade do cônjuge sobrevivente para representar o cônjuge pré-morto em direito sucessório".

Percebe-se, do acórdão acima colacionado, que o cônjuge sobrevivente não concorre com os descendentes (ou demais herdeiros) na herança do sogro/sogra pós-morto ao cônjuge já falecido. Ou seja, não há recebimento de herança da nora/do genro sobrevivente na herança do sogro/sogra.

Importante mencionar aqui, voltando para o tema central deste trabalho, a questão das relações de padrastio e madrastio. O Código Civil não traz em seu bojo um conceito ou um estabelecimento de certas responsabilidades ou até mesmo uma parcela do poder familiar aos padrastos e madrastas.

Sabe-se que, na atualidade, muitas famílias se recompõem, e os filhos veem-se em um novo núcleo familiar por conta de uma nova união de seus genitores. Com isso, muitas vezes, os padrastos e madrastas exercem um papel ou uma função de pai e mãe na vida de seus filhos.

Enquanto esse novo relacionamento de seus genitores está bem, talvez não existam questões a serem resolvidas - eventualmente, na questão de prática de alienação parental, desejo de inserir o nome dos padrastos e madrastas aos dos filhos, algo nesse sentido. O problema maior surge quando esse relacionamento é rompido - questões afetas aos alimentos, herança deixada em testamento, reconhecimento de filiação pela socioafetividade entre outros.

Eis o ponto deste artigo. Estariam o padrasto e a madrasta obrigados a prestar alimentos aos seus enteados? Essa obrigação derivaria de qual vínculo jurídico? O problema surge porque a filiação ou o parentesco se estabelecem após o reconhecimento jurídico de um filho - seja de forma voluntária ou não.

Antes de mais nada, faz-se necessário adentrar um pouco mais na temática da socioafetividade. Entende Christiano Cassettari (2014, p. 28) que a família moderna é socioafetiva, pois elevou o afeto a uma 
categoria jurídica, dados seus efeitos jurídicos, de maneira que "A paternidade ou filiação socioafetiva é o reconhecimento judicial de que o que liga duas pessoas e as faz crer que manterão esse vínculo por toda a vida é o amor" (SCalquette, 2010, p. 44).

Nas recomposições familiares, a partir da convivência de seus atuais membros, segundo afirma Caio Mário da Silva Pereira (2013, p. 36), existe uma nova relação de parentesco (advinda da morte ou da separação/divórcio), de modo que esse parentesco por afinidade assume funções próprias da família biológica, e o papel assumido pelos genitores afins é o de participação em um processo de socialização, de sustento material e educação.

O enteado, nas famílias recompostas, muitas vezes é conhecido como filho de 'fulano de tal', ou seja, existe nessas relações a chamada posse de estado de filho, na qual os enteados são conhecidos perante a sociedade e tratados como filhos de seus padrastos ou madrastas. Muitas vezes são estes que sustentam e dão todo suporte material (e até mesmo emocional) aos enteados.

Segundo a doutrina italiana, no mesmo sentido, devem concorrer três circunstâncias: a de que a pessoa tenha carregado o nome de quem pretende ter como genitor (nomen), que fosse tratada, mantida e considerada como filho no trato social (tractatus) e ainda que essa qualidade fosse reconhecida pela família (fama) (PINO, 1998, p. 191 - 192) (tradução livre) ${ }^{2}$.

O Código Civil Francês, ao tratar da posse de estado de filho, em seu Art. 311-1, descreve alguns fatos que revelam esse estado. O primeiro é o tratamento de pai e filho entre as partes e que os pais tenham participado da educação e formação do filho; que esses filhos

2 Tradução livre do texto: “(...) Con questi fatti, devono sempre concorrere tre circostanze: che la persona abbia portato il cognome di quella che pretende di avere come genitore (nomen); che da quest'ultima sia stata trattata, mantenuta e considerata come figlio nei rapporti social (tractatus) e, in detta qualità, sia stata riconosciuta dalla famiglia (fama) (art. 237). 
sejam reconhecidos como seus, perante a sociedade, a família e perante a autoridade pública; que ele tenha o nome daquele a quem se pretenda provar o estado de filho. Deve a posse de estado ser contínua, pacífica, pública e inequívoca (Art. 311-2) (Code CiviL). ${ }^{3}$

Ocorre que esse exercício da função parental (socioafetiva), sem o reconhecimento jurídico de tal qualidade (pai ou mãe registrais), não gera os mesmos efeitos que um filho com vínculo reconhecido. Sendo assim, afirma Fujita (2013, p. 81) que os filhos de criação seriam equiparados “(...) a uma adoção informal ou de fato”.

Deste modo, poder-se-ia afirmar que o ordenamento reconhece a filiação socioafetiva com os efeitos jurídicos dela decorrentes, prevista na parte final do art. 1593, podendo ser estabelecida de forma voluntária (judicial ou extrajudicial) ou contenciosa, na via judicial.

Como ficariam então esses filhos que foram criados tanto com suporte material quanto emocional por seus padrastos e madrastas, sem terem o reconhecimento jurídico da filiação? Estariam desamparados?

Neste contexto, poder-se-ia mencionar a possibilidade de um vínculo de parentalidade socioafetivo informal, calcado na posse de estado de filhos ainda não reconhecidos, para os efeitos jurídicos que possam advir para embasar eventual pedido de alimentos? É o que se pretende discutir no item a seguir.

3 Tradução livre do texto: “Article 311-1 'La possession d'état s'établit par une réunion suffisante de faits qui révèlent le lien de filiation et de parenté entre une personne et la famille à laquelle elle est dite appartenir.

Les principaux de ces faits sont: $1^{\circ}$ Que cette personne a été traitée par celui ou ceux dont on la dit issue comme leur enfant et qu'elle-même les a traités comme son ou ses parents; $2^{\circ}$ Que ceux-ci ont, en cette qualité, pourvu à son éducation, à son entretien ou à son installation; $3^{\circ}$ Que cette personne est reconnue comme leur enfant, dans la société et par la famille; $4^{\circ}$ Qu'elle est considérée comme telle par l'autorité publique; $5^{\circ}$ Qu'elle porte le nom de celui ou ceux dont on la dit issue.' Article 311-2 'La possession d'état doit être continue, paisible, publique et non équivoque." CODE CIVIL. op. cit., loc. cit. 


\section{ALIMENTOS NAS RELAÇÕES DE PADRASTIO E MADRASTIO: UMA NECESSÁRIA RELEITURA}

O direito aos alimentos possui natureza especial, já que é vinculado aos direitos fundamentais da pessoa humana, como o direito à vida e ao sustento. Com base em alguns princípios constitucionais, que tratam do direito de família e possuem relação com os alimentos, estão: princípio da dignidade da pessoa humana, da solidariedade, da fraternidade, da igualdade jurídica entre os filhos, melhor interesse da criança e do adolescente e outros (CARdoso, 2018, p. 21).

Com o propósito de assegurar os recursos necessários à subsistência de quem não consegue por si só prover sua manutenção pessoal, a obrigação alimentar está fundada em obrigação de interesse superior, com caráter de ordem pública (Madaleno, 2017, p. 898).

A Constituição Federal traz no Art. 227 como dever da família, sociedade e Estado (ou seja, tríplice responsabilidade) o dever de assegurar à criança, ao adolescente e ao jovem, entre outros direitos, o direito à alimentação (Constituição Federal 1988).

Assim, sob esse viés constitucional, que impõe um dever a sociedade como um todo, ao Estado, mas em especial à família, de assegurar alimentos aos membros que a compõem. Isso porque existe uma solidariedade que vincula esses três atores, em especial a família, que deve trazer o dever de socorro, de sustento, aos seus integrantes.

De acordo com o art. 1.694 do CC "podem os parentes, os cônjuges ou companheiros pedir uns aos outros os alimentos de que necessitem para viver de modo compatível com a sua condição social, inclusive para atender às necessidades de sua educação" (CóDigo Civil, 2002).

Os alimentos abrangem, portanto, a satisfação de todas as necessidades materiais, morais, culturais, educacionais e de moradia do alimentando, sendo cabíveis entre parentes. Consoante art. 1.696 do CC “o direito à prestação de alimentos é recíproco entre pais e 
filhos" (Código Civil, 2002). Com o estabelecimento do vínculo registral, seja oriundo de laços biológicos ou socioafetivos, decorrem automaticamente todos os direitos e deveres inerentes à relação paterno (materno)-filial.

Se, durante algum tempo, houve incerteza acerca do reconhecimento e efeitos jurídicos decorrentes da filiação socioafetiva, mas após a análise do tema pelo Supremo Tribunal Federal, não mais restam dúvidas. No julgamento do leading case (Recurso Extraordinário n. 898.060 e Repercussão Geral 622), com aprovação de tese histórica de que "a paternidade socioafetiva, declarada ou não em registro, não impede o reconhecimento do vínculo de filiação concomitante, baseada na origem biológica, com os efeitos jurídicos próprios”, foi reconhecida não só a possiblidade da multiparentalidade, como também a inexistência de prevalência da filiação biológica sobre a socioafetiva (Rosa, 2021).

Logo, é questão pacífica o direito aos alimentos entre filhos e pais, independente da origem de vínculo - consanguíneo ou socioafetivo - basta que seja formalizado. Celeuma que surge, então, diz respeito à possibilidade de alimentos decorrentes do vínculo de afinidade, entre padrasto (madrasta) e enteado(a).

A realidade fática dos arranjos familiares contemporâneos - caso das famílias mosaico - é capaz de criar cenários com novos personagens e atribuição de papéis em moldes distintos do codificado, conforme já mencionado. Como exemplo, segundo o Censo Demográfico do IBGE, de 2010 (último censo a levantar esses dados), 16,3\% do total de famílias brasileiras são consideradas reconstituídas, o que totalizava 4,4 milhões de famílias nesse novo formato. O estudo, realizado já há mais de dez anos, apontava também de que 2,5 milhões de crianças viviam com os padrastos ou madrastas (IBGE, 2010). De lá para cá, muito possivelmente, esse número deve ter aumentado.

4 Enunciado n. 341 do CJF "Para fins do art. 1.696, a relação socioafetiva pode ser elemento gerador de obrigação alimentar”. 
Isso interfere diretamente nas funções desempenhadas pela família que, ao longo do tempo, moldaram-se de acordo com as necessidades pessoais e coletivas. $\mathrm{Na}$ atualidade, fala-se da função social da família ou função socioafetiva, calcada na solidariedade e no afeto entre os seus membros, exigindo relações mais humanizadas e, portanto, condizentes com a realidade social e com os fundamentos constitucionais vigentes (GHILARDI, 2015).

Segundo Rolf Madaleno (2017, p 89), a solidariedade é oxigênio de todas as relações familiares e afetivas, "porque esses vínculos só podem se sustentar e desenvolver em ambiente recíproco de compreensão e cooperação, ajudando-se mutuamente sempre que se fizer necessário".

Nessa linha de intelecção, a pluralidade familiar e a igualdade assegurada entre as entidades familiares, alicerçadas no artigo 227 da CFRB/88, realizadoras da própria dignidade da pessoa humana, requerem que os sujeitos tenham assegurado seu histórico diário e condição social vivenciada. Tanto que estão a exigir desenhos de soluções em conformidade com o destacado papel social e familiar ocupados pelos padrastos e madrastas.

Em reforço ao argumento, a Doutrina da Proteção Integral, afirma o respeito à condição da criança e do adolescente como sujeito em desenvolvimento, bem como o reconhecimento da sua vulnerabilidade, que as transforma em merecedoras de proteção integral pela família, sociedade e Estado (Veronese, 2019).

Dentro desse contexto, alçadas as crianças e adolescentes a sujeitos de direito, as garantias que lhe são inerentes ao pleno amadurecimento de sua personalidade, devem ser observadas também no contexto das famílias reconstituídas, inseridas as necessidades materiais e afetivas (Vítor, 2016).

Para isso, urge a reestruturação de algumas categorias jurídicas ou, ao menos, a ampliação de sua interpretação, para que seja viável sintonizar com algumas exigências do século XXI. Com relação ao poder familiar, por exemplo, é preciso uma nova compreensão de 
seu conceito, desmembrando a titularidade do exercício, para que seja possível a adequação do instituto à dinâmica posta pelas famílias recompostas. Enquanto a titularidade é exclusiva dos pais, conforme previsão legal, o exercício efetivo, desses poderes-deveres (educação, cuidados, sustento), na prática, não raro é desempenhado pelos padrastos ou madrastas (MADALENo, 2017, p. 940).

Tanto que o Código Civil Português (Art. 1904-A, inc I) e o Alemão, já atentos a essa realidade, preveem expressamente a possibilidade de extensão do exercício conjunto das responsabilidades parentais, porém, somente nos casos de filiação unilateral no registro (CAstro, 2018).

No Brasil, embora o Código Civil não mencione nada a respeito de poderes análogos ao poder familiar aos padrastos, merece destaque a Lei n. 11.924, em 2009, que alterou a Lei de Registro Civil - Lei n. 6.015/73 - e passou a autorizar ao enteado(a) a inserção, no registro de nascimento, do nome de família do padrasto ou madrasta, desde que haja expressa concordância destes.

Essa regra dá um passo importante em direção ao reconhecimento do laço de socioafetividade, criado a partir do vínculo de afinidade, podendo, inclusive, resultar em prova a auxiliar na comprovação do parentesco, já que a socioafetividade, para gerar algum efeito, requer o estabelecimento formal do vínculo e, para isso, depende da comprovação dos requisitos da posse de estado de filho (nome, tratamento e fama).

Dando sequência, e com intuito de enfrentar a problematização da presente investigação, passa-se agora à análise legal, jurisprudencial e de experiências estrangeiras sobre a questão dos alimentos propriamente dita. A respeito da legislação brasileira, percebe-se a não obrigatoriedade do dever de prestar alimentos entre padrasto/madrasta e enteado(a), seja durante a convivência familiar, seja após o rompimento dos laços conjugais, pouco importando se houve a assunção da responsabilidade pelo sustento ou não dos enteados.

O Código Civil português, a seu turno, já avançou no sentido de reconhecimento de alguns efeitos decorrentes dos vínculos de 
afinidade (em Portugal não há reconhecimento de vínculo socioafetivo), prevendo expressamente a obrigação de alimentos entre padrasto e enteados menores de idade quando da morte do cônjuge, caso estivessem os enteados a cargo deste (artigo 2009, n.1, al. fCCiv) (Campos; Campos, 2018).

Do Código Civil alemão também é possível observar a previsão de obrigação do padrasto prestar alimentos em caso de morte do progenitor, direcionada à sua formação adequada (par. 11371 (4) BGB) (VÍtor, 2016).

Já nas situações de rompimento do vínculo conjugal, seja decorrente de divórcio, separação, anulação ou nulidade de casamento ou cessação da coabitação entre os corresponsáveis parentais, há uma tímida previsão de alimentos aos enteados na codificação portuguesa, se o padrasto tivesse assumido a responsabilidade parental conjuntamente com a genitora da criança, ao longo da relação, e caso o vínculo fosse unilateral. Todavia, o art. 2009, n. 5 coloca o padrasto em último lugar na lista dos responsáveis, ou seja, a responsabilidade alimentar recairá sobre o padrasto apenas em caso de impossibilidade financeira dos demais parentes (ascendentes, irmãos ou tios) (Vítor, 2016, p. 627).

Com efeito, ressalvada a ocorrência da morte da genitora, nas demais situações de ruptura da relação conjugal, os enteados também estão desprotegidos em Portugal e na Alemanha, tal qual no Brasil. Isso reflete diretamente na vida dos enteados, porquanto a ausência de continuidade de sustento por parte do padrasto ou madrasta - que livremente assumiram a incumbência ao longo da relação - pode causar prejuízos ao saudável desenvolvimento daqueles.

Embora o Código Civil brasileiro seja de 2002, no que diz respeito ao direito de família, principalmente, seu texto já está bastante defasado. Grande parte das atualizações aqui ocorridas - a exemplo das uniões homoafetivas e da multiparentalidade - derivam de decisões dos Tribunais.

O fenômeno da jurisprudencialização, responsável pela acentuação do espaço dado aos precedentes, torna imperiosa a observação da 
interpretação dada pelo Judiciário às ações de alimentos ingressadas pelos enteados em relação aos padrastos.

Nesse passo, a investigação deu-se nos sítios dos Tribunais de Justiça de Santa Catarina, Rio Grande do Sul, Distrito Federal e São Paulo. Os termos de busca foram "alimentos" e "padrasto" e, na sequência, "alimentos" e "pai socioafetivo", no formato pesquisa livre-ementa. O resultado, após exclusão da maioria dos julgados encontrados, em razão de se tratar de ações e ou discussões distintas da pretendida, apresentou somente 02 julgados do Tribunal catarinense, 02 julgados do Tribunal gaúcho e 02 julgados do TJDF, não havendo nenhum do Tribunal de Justiça paulista.

O TJRS foi o Tribunal que apontou postura mais restritiva ao acolhimento do pleito de alimentos a enteado(a) ou filho socioafetivo. No caso julgado em 2019 (TJRS, 2019) ${ }^{5}$ houve o indeferimento da inicial, por inépcia, diante da ilegitimidade do padrasto para prestar alimentos. O voto foi pelo descabimento de fixação de alimentos, fundada no dever de assistência decorrente do poder familiar, obrigação de responsabilidade apenas dos genitores. Apesar da postura contundente, é possível extrair de que o pleito alimentar poderia ser exitoso, caso tivesse sido precedido de ação de reconhecimento de filiação socioafetiva, com pedido acolhido.

Também no sentido de impossibilidade de alimentos, sem anterior relação de parentesco, observou-se o entendimento do TJDF

5 APELAÇÃO CÍVEL. AÇÃO DE ALIMENTOS. INDEFERIMENTO DA INICIAL, POIS INEPTA. ILEGITIMIDADE DO PADRASTO PARA PRESTAR ALIMENTOS RECONHECIDA. PLEITO DE REFORMA DA DECISÃO, COM O REGULAR PROSSEGUIMENTO DO FEITO. DESCABIMENTO. SENTENÇA MANTIDA. I. Não sendo filha biológica e/ou registral do apelado, descabida a fixação de alimentos em favor da apelante com fundamento no dever de assistência decorrente do poder familiar, devendo serem prestados por seus pais, como já faz o genitor biológico. (...) Ausência de vínculo jurídico prévio a autorizar a pretensão da apelante, que, no presente feito, diz respeito exclusivamente à fixação de pensionamento. Apelação desprovida, por maioria. (Apelação Cível, N 70080991995, Oitava Câmara Cível, Tribunal de Justiça do RS, Relator: José Antônio Daltoe Cezar, Julgado em: 27-06-2019). 
$(2016)^{6}$. Do julgado pode-se verificar que a "necessidade de pedido de reconhecimento de vínculo socioafetivo entre o requerido e o menor, de modo a justificar o dever de prestação alimentícia”, revelando-se razoável a propositura de demanda específica. Ou seja, os alimentos são consequência de anterior vínculo parental devidamente constituído em demanda própria, não cabendo o reconhecimento de vínculo socioafetivo em ação de alimentos.

Já no julgado de 2020, do TJRS, que tratava de dissolução de união estável com pedido de declaração sociafetiva e alimentos, a sétima câmara entendeu de que "somente existe paternidade socioafetiva quando alguém assume a condição de pai voluntariamente, sabendo da inexistência de liame biológico". O caso sub judice analisou, ainda, a relação entre enteado e padrasto, e conclui que o carinho e atenção despendidos pelo padrasto, bem como a assunção do sustento e educação do enteado, durante a relação com a genitora deste, "não tem o condão de transformar o padrasto em pai, nem constitui título jurídico capaz de habilitar o enteado para pleitear alimento em seu favor" (TJRS, 2020). ${ }^{7}$

${ }^{6}$ CIVIL E APELAÇÃO CIVIL. FAMÍLIA. PATERNIDADE SÓCIOAFETIVA. RECONHECIMENTO NA DEMANDA DE ALIMENTOS. NÃO CABIMENTO. FIXAÇÃO DE ALIMENTOS SEM A RELAÇÃO DE PARENTESCO. IMPOSSIBILIDADE. PENSÃO ALIMENTÍCIA. DEVER DOS PAIS. BINÔMIO NECESSIDADE/POSSIBILIDADE. REDUÇÃO DO VALOR FIXADO. QUANTUM DETERMINADO EM SENTENÇA.ADEQUAÇÃO. 1. A instituição de obrigação de natureza alimentar, no âmbito do Direito de Família, pressupõe a existência de uma relação jurídica que lhe dê causa - no caso, o dever de sustento dos pais com a prole ou de um parente em relação a outro (arts. 1.566 e 1.634 CCB/2002).2. Verifica-se a necessidade de pedido de reconhecimento de vínculo sócioafetivo entre o requerido e o menor, de modo a justificar o dever de prestação alimentícia e, portanto, revela-se razoável a propositura de demanda específica, incluindo no polo passivo da demanda o pai biológico do menor. (...) (TJDF, Relator(a) Carlos Rodrigues Processo: 20151110024972APC, j. 17/08/2016, 6 Turma Cível).

7 AÇÃO DE DISSOLUÇÃO DE UNIÃO ESTÁVEL COM PEDIDO DE DECLARAÇÃO DE PATERNIDADE SOCIOAFETIVA. ALIMENTOS PROVISÓRIOS EM FAVOR DO ENTEADO. TUTELA PROVISÓRIA. DESCABIMENTO. 1. (...) 2. É cabível o reconhecimento forçado da filiação quando o genitor deixa de reconhecer voluntariamente 
Da leitura dos acórdãos citados, fica claro que o cabimento de alimentos depende da relação de parentalidade, a qual deve ser constituída de forma antecedente ao pleito alimentar. Também é possível denotar que o estabelecimento do parentesco socioafetivo somente é possível se decorrente de voluntariedade do padrasto, não podendo ser imposto judicialmente, ainda que o padrasto tenha assumido o sustento ao longo da convivência conjugal.

Já o TJSC, nos dois julgados encontrados, mostrou-se favorável à tese de cabimento de alimentos nas relações de padrastio, sempre que presente a comprovação da sociafetividade, assim como um dos julgados mais recentes do TJDF. Nestas decisões, o entendimento foi o oposto das acima analisadas, entendo os julgadores perfeitamente possível o reconhecimento da socioafetividade, ainda que contrariando a vontade do padrasto, quando presentes os requisitos da posse de estado de filho.

Em análise ao recurso de decisão oriunda da Comarca de São José - SC, apontada como o primeiro caso brasileiro de reconhecimento de fixação de verba alimentar devida pelo padrasto à enteada, o TJSC manteve a decisão de primeiro grau que, em ação de reconhecimento e dissolução de união estável cumulada com alimentos, fixou verba alimentar à enteada. Observa-se de que "comprovado o vínculo socioafetivo e a forte dependência financeira entre padrasto e a menor, impõe-se a fixação de alimentos em prol do dever contido no art. 1.694 do Código Civil." 8

o seu filho biológico, pois não é possível impor a alguém o estabelecimento de filiação adotiva, nem socioafetiva, pois, para tanto, é imprescindível a voluntariedade do ato. 3. Somente existe paternidade socioafetiva quando alguém assume a condição de pai voluntariamente, sabendo da inexistência do liame biológico. Recurso provido. (Agravo de Instrumento, No 70083402644, Sétima Câmara Cível, Tribunal de Justiça do RS, Relator: Sérgio Fernando de Vasconcellos Chaves, Julgado em: 28-04-2020).

8 AÇÃO DE RECONHECIMENTO E DISSOLUÇÃO DE UNIÃO ESTÁVEL C/C ALIMENTOS. (...) ALIMENTOS À ENTEADA. POSSIBILIDADE. VÍNCULO SOCIOAFETIVO DEMONSTRADO. PARENTESCO POR AFINIDADE. (...) Comprovado o vínculo socioafetivo e a forte dependência financeira entre padrasto e 
Em outro julgado, de 2016 (TJSC) ${ }^{9}$, confirmou-se novamente a possibilidade de fixação de verba alimentar em favor dos enteados. Em ação de alimentos proposta pela ex-companheira e por dois filhos dela (enteados do demandado), o tribunal manteve sentença de pensionamento alimentar. Em análise ao vínculo estabelecido, os julgadores ressaltaram o tempo de convívio (quase 16 anos) entre padrasto e enteados, o qual teria gerado afeição recíproca, caracterizadora da denominada paternidade socioafetiva (teoria da posse de estado de filho). Destacou-se, ainda, a conduta do demandado, comprometida, desde cedo, com "a dignidade, a saúde e principalmente a educação das crianças, viabilizando-lhes todas as oportunidades e necessidades ansiadas pelos jovens contemporâneos, inclusive, intercâmbio internacional".

A recente decisão do TJDF $(2021)^{10}$ em ação de alimentos, com reconhecimento incidental de paternidade socioafetiva, também

a menor, impõe-se a fixação de alimentos em prol do dever contido no art. 1.694 do Código Civil. (...) DECISÃO MANTIDA. RECURSO IMPROVIDO. (TJSC, Agravo de Instrumento n. 2012.073740-3, de São José, rel. João Batista Góes Ulysséa, Segunda Câmara de Direito Civil, j. 14-02-2013).

9 APELAÇÃO CÍVEL. DIREITO DE FAMÍliA. ALIMENTOS. DEMANDA PROPOSTA PELA EX-COMPANHEIRA E POR DOIS FILHOS DELA (ENTEADOS DO DEMANDADO). SENTENÇA FIXADORA DE PENSIONAMENTO ALIMENTAR TEMPORÁRIO Å EX-CONVIVENTE E À ENTEADA (...) ENTEADOS QUE, DESDE TENRA IDADE (A MENINA E O MENINO CONTANDO COM TRÊS E CINCO ANOS DE IDADE, RESPECTIVAMENTE), CONVIVERAM NA NOVA FAMÍLIA FORMADA PELA MÃE E PELO DEMANDADO, POR QUASE DEZESSEIS ANOS, AFEIÇOANDO-SE UNS (OS INFANTES) AO OUTRO (O PADRASTO), DE MODO A CARACTERIZAR, COM RIQUEZA DE DETALHES, A DENOMINADA PATERNIDADE SOCIOAFETIVA (TEORIA DA POSSE DO ESTADO DE FILHO). SENTENÇA IMPECÁVEL. (...) (TJSC, Apelação Cível n. 2015.050506-3, de Rio do Sul, rel. Eládio Torret Rocha, Quarta Câmara de Direito Civil, j. 17-03-2016).

10 APELAÇÃO CÍVEL. AÇÃO DE ALIMENTOS. RECONHECIMENTO INCIDENTAL DA PATERNIDADE SOCIOAFETIVA. EXISTÊNCIA DE VÍNCULO AFETIVO. COMPROVAÇÃO. OBRIGAÇÃO DE CONTRIBUIR COM O SUSTENTO. SENTENÇA MANTIDA. 1. A situação fática delineada nos autos não deixa dúvidas sobre a existência de vínculo afetivo à época em que as partes 
assentiu com o pedido alimentar em favor de enteados, uma vez comprovada a relação de sociafetividade. Analisando o julgado, observa-se que "verificada a formação do vínculo socioafetivo, necessário se faz compelir o réu a obrigação de contribuir com o sustento dos autores, em razão do poder familiar configurado."

Em análise geral dos julgados compilados, embora ainda em pequeno número, observam-se posturas bem distintas entre os julgadores no tocante ao cabimento ou não de alimentos derivadas dos vínculos de afinidade entre padrasto (madrasta) e enteado(a), ensejando grande insegurança quanto ao desfecho de demandas semelhantes, o que faz aumentar ainda mais a necessidade de se criar parâmetros de cabimento da verba alimentar, decorrentes de relações familiares reconstituídas.

Contudo, é possível concluir que distintos cenários são apresentados e as soluções, em geral, pautam-se por meio de alguns argumentos. Portanto, com a pretensão de auxiliar na resolução da questão proposta nesta investigação, apresentam-se nesse momento duas situações distintas observadas: a) a relação existente entre o(a) filho(a) da genitora e seu parceiro configura relação de afinidade, inexistindo vínculo de afeto e não sendo as despesas do(a) filho arcadas pelo padrasto durante a relação; b) a relação existente entre o(a) filho(a) da genitora e seu parceiro configura relação de afinidade, com a existência de laços de afeto, sendo as despesas deste(a) arcadas pelo padrasto durante a relação;

conviveram, caracterizando paternidade socioafetiva, uma vez que as partes agiam e se identificavam socialmente como pai e filhos. 2. Não cumpre ao Judiciário impor sentimentos às partes, embora inegavelmente o amor seja desejável nas relações de parentesco. Entretanto, os direitos e obrigações decorrentes da filiação não se cingem à esfera afetiva, havendo inegáveis implicações nas esferas psicológica, patrimonial, social, registral, pessoal, civil, dentre outras. 4. Verificada a formação do vínculo socioafetivo, necessário se faz compelir o réu a obrigação de contribuir com o sustento dos autores, em razão do poder familiar configurado. 5. Recurso desprovido. (TJDF, Relator: JOSAPHA FRANCISCO DOS SANTOS, Proc. 0004645372016807002, jul. 02/06/21, 5 Turma Cível). 
Dessarte, se no passado reconhecedor de vínculos exclusivamente biológicos, a união conjugal com alguém que tivesse filhos revelava tão somente as figuras do padrasto, da madrasta e enteado(a), hoje, essa mesma união pode ser responsável pelo surgimento das figuras de pai(mãe) e filho(a) afetivo. A linha que os separa é bastante tênue e depende de prova apta a caracterizar a posse de estado de filiação, consolidada ao longo do tempo e, em princípio, permissiva de conversão do vínculo de afinidade em paternidade propriamente dita.

Sob essa óptica, importa compreender esse novo fenômeno e tratá-lo adequadamente, de modo a garantir o cumprimento adequado das funções familiares contemporâneas (MADALENO, 2017, p. 941), eis que de uma mera relação de afinidade, sem efeitos jurídicos, pode haver a mutação para um vínculo de parentesco, assegurados todos os direitos e garantias da relação paterno-filial.

A relação de padrastio apresenta mais resistência no tocante à imposição de alimentos, todavia, reconhecida e comprovada a transformação do vínculo em socioafetividade (posse de estado de filho), mesmo diante da ausência de obrigatoriedade legal, o pleito alimentar reveste-se de maiores possibilidades de aceitação, segundo indicam os julgados avaliados.

Desse modo, deduz-se de que o vínculo autorizador de alimentos não decorre das responsabilidades parentais do padrasto (madrasta) até porque inexistentes na lei-nem somente do exercício fático dessas responsabilidades, mas sim da conjugação da assunção de deveres parentais e do estabelecimento de vínculo afetivo entre enteado(a) e padrasto (pai ou mãe socioafetiva).

Ora, se laços afetivos foram criados e se o cônjuge ou companheiro assumiu espontaneamente o dever de sustento do filho de sua(seu) cônjuge ou companheira (o) durante a relação de conjugalidade, e se a interrupção dessa verba comprometer o bem-estar do(a) enteado(a) menor de idade ou dependente, não parece nem um pouco razoável a exoneração da responsabilidade, seja pelo dever de solidariedade 
presente entre os membros da unidade familiar, seja em decorrência da doutrina da proteção integral de crianças e adolescentes.

Nesse passo, andou bem o novo Código Civil e Comercial Argentino (Lei 26.994/2014). A referida legislação prevê a possiblidade de contribuição alimentar do cônjuge, quanto aos filhos do outro, ao longo da relação, com previsão de cessação diante da ruptura, salvo se o padrasto tenha assumido o sustento e a suspensão causar grave prejuízo ao enteado (CARAmelo, 2016). ${ }^{11}$

De significativa relevância faz-se tal previsão, uma vez que projeta os efeitos do vínculo de padrastio para o momento de ruptura da relação conjugal, diante da caracterização de duas circunstâncias bem objetivas: a assunção espontânea do padrasto do dever de sustento ao longo da união e o grave prejuízo provocado pela suspensão desse sustento.

Essa alternativa encontra sustentação na CFRB/88 que prioriza o bem-estar de crianças e adolescentes, assegurando-lhes todas as garantias para o seu saudável desenvolvimento.

\section{CONCLUSÃO}

A lei, editada sob fundamentos arcaicos, preocupou-se em estabelecer direitos e deveres apenas entre pais e filhos. Aos genitores foi concedida a detenção exclusiva do poder familiar, recaindo sobre eles a obrigatoriedade do dever de sustento dos filhos. Conforme já ressaltado no texto, o direito pensado e construído no passado, em que a família era unitária, decorrente tão somente do casamento e

11 Art. 676 do Codigo Civil y Comercial da Argentina. "Alimentos. La obligación alimentaria del cónyuge o conviviente respecto de los hijos del otro, tiene carácter subsidiario. Cesa este deber en los casos de disolución del vínculo conyugal o ruptura de la convivencia. Sin embargo, si el cambio de situación puede ocasionar un grave daño al niño o adolescente y el cónyuge o conviviente asumió durante la vida en común el sustento del hijo del otro, puede fijarse una cuota asistencial a su cargo con carácter transitorio, cuya duración debe definir el juez de acuerdo a las condiciones de fortuna del obligado, las necesidades del alimentado y el tiempo de la convivência”. 
com as funções de pai e mãe bem demarcadas, não dá mais conta da complexidade da sociedade contemporânea.

É preciso, com urgência, observar os novos formatos de entidades familiares e adequar as exigências legais. Já se avançou no que diz respeito aos vínculos de parentalidade, outrora reservados à biologia ou ao vínculo civil. Os laços de afeto hoje também são constituintes de vínculos de parentesco, inclusive podendo ser concomitantes, resultando a multiparentalidade. Porém, com o aumento do número de divórcios e dissoluções de uniões estáveis, aumentou também o número de famílias mosaico. Essa realidade não pode ser desprezada.

Se as crianças, no Código Civil de 1916, não tinham lugar de destaque e nem voz, a partir da CRFB/88 passaram a ser consideradas sujeitos de direito, resguardado o seu superior interesse. Os assuntos de família, antes reservado aos adultos, hoje devem ser pautados pela Doutrina da Proteção Integral.

Portanto, a resposta ao questionamento formulado se são cabíveis alimentos entre padrasto (madrasta) e enteado(a) depende da análise realizada, se legal ou jurisprudencial. A lei não prevê a obrigatoriedade. Os Tribunais brasileiros pouco se manifestaram sobre o tema. Nos julgados encontrados, todavia, percebe-se entendimentos dissonantes.

Ainda assim, é possível extrair algumas conclusões: a) a simples relação de padrastio ou madrastio não comporta a obrigatoriedade alimentar; b) a conversão dessa relação de afinidade em relação de socioafetividade cria o vínculo necessário para o estabelecimento dos alimentos, contudo, a discussão acontece sobre a possiblidade ou impossibilidade de reconhecimento forçado desse vínculo.

Para que a dúvida não dependa apenas de interpretação judicial e segundo a convicção dos julgadores, modificação legal nos moldes da legislação argentina seria bem-vinda. Enquanto isso não acontece, os parâmetros objetivos exigidos pelo país vizinho podem balizar os rumos da discussão no Brasil, trazendo maior segurança jurídica.

A solução encontrada pelo direito argentino, consentânea com o perfil socioafetivo das novas famílias, salvaguarda o bem-estar e 
as necessidades da criança e do adolescente como referência e limite para a imposição da obrigatoriedade alimentar, em equilíbrio com o ônus imposto ao padrasto, que será cabível somente diante de situação pretérita de assunção espontânea de responsabilidade de sustento.

\section{REFERÊNCIAS}

ALMEIDA, José Luiz Gavião de. Reconhecimento de filiação. In: SIMÃO, José Fernando; FUJITA, Jorge Shiguemitsu; CHINELLATO, Silmara Juny de Abreu; ZUCCHI, Maria Cristina. (org.) Direito de família no novo milênio: estudos em homenagem ao professor Álvaro Villaça Azevedo. São Paulo: Atlas, 2010.

BAUMANN, Zigmund. Modernidade Líquida. Tradução Plínio Dentzien. Rio de Janeiro: Jorge Zahar, 2001.

BARBOZA, Heloísa Helena. Efeitos Jurídicos do Parentesco Socioafetivo. In: Revista da Faculdade de Direito da UERJ - RFD, v. 2., n. 24, 2013. BOBBIO, Norberto. Teoria do Ordenamento Jurídico. Brasília: Universidade de Brasília, 1999.

BITTAR, Eduardo, C. B. O Direito na Pós Modernidade. 3. ed. São Paulo: Atlas, 2014.

CAMPOS, Diogo de; CAMPOS, Monica Martinez. Lições de Direito da Família. Coimbra: Almedina, 2018.

CASSETTARI, Christiano. Multiparentalidade e parentalidade socioafetiva: efeitos jurídicos. São Paulo: Atlas, 2014.

CARAMELO, Gustavo; HERRERA, Marisa; PICASSO, Sebástian. Código Civil y Comercial de la Nación comentado. 2. ed. Ciudad Autónoma de Buenos Aires: Infojus, 2016.

CARDOSO, Fabiana Domingues. A indignidade no direito aos alimentos. São Paulo: Iasp, 2018.

CASTRO, Sara Emanuela Vieira de Castro. A relação entre padrasto e enteado: direitos e deveres. Dissertação de Mestrado. Faculdade de Coimbra: 2018 
COSTA, Mário Júlio de Almeida. Noções fundamentais de direito civil. 6. ed. Coimbra: Almedina, 2013.

FACHIN, Luiz Edson. Estabelecimento da filiação e paternidade presumida. Porto Alegre: Fabris, 1992.

FARIAS, Cristiano. ROSENVALD, Nelson. Curso de Direito Civil: Famílias. 13. ed. Salvador: Jus Podivm, 2021.

FARIAS, Cristiano Chaves de. A família parental. In: PEREIRA, Rodrigo da Cunha. (org.). Tratado de Direito das Famílias. Belo Horizonte: IBDFAM, 2015.

FUJITA, Jorge Shiguemitsu. Filhos de criação: e os seus direitos? In: CASSETTARI, Christiano. (coord). VIANA, Rui Geraldo Camargo de. (orient.) 10 anos de vigência do Código Civil de 2002: estudos em homenagem ao professor Carlos Alberto Dabus Maluf. São Paulo: 2013. Saraiva.

GHILARDI, Dóris. Economia do Afeto: Análise Econômica aplicada ao Direito de Família. Rio de Janeiro: Lumen Juris, 2015.

GROSSI, Paulo. Mitologias jurídicas da modernidade. Tradução de Arno Dal Ri Júnior. Florianópolis: Fundação Boiteux, 2007. Título original: Mitologiegiuridichedellamodernitá.

MELO, Osvaldo Ferreira. Fundamentos da Política Jurídica. Porto Alegre: Sergio Fabris, 1994.

ROSA, Conrado. Paulino da. Direito de Família Contemporâneo. 8. ed. Salvador: Jus Podivm, 2021.

PAIANO, Daniela Braga. O direito de filiação nas famílias contemporâneas. 2016. Tese (Doutorado em Direito Civil) - Faculdade de Direito, Universidade de São Paulo, São Paulo, 2016.

PEREIRA, Caio Mário da Silva. Instituições de Direito Civil. Rio de Janeiro: Forense, 2013.

PINO, Augusto. Diritto di famiglia. 3. ed. Padova: CEDAM, 1998.

TEPEDINO, Gustavo; TEIXEIRA, Ana Carolina Brochado. Fundamentos do Direito Civil, Vol. 6. Direito de família. Rio de Janeiro: Forense, 2020.

SCALQUETTE, Ana Cláudia Silva. Estatuto da reprodução assistida. São Paulo: Saraiva, 2010. 
SCALQUETTE, Ana Cláudia Silva. Família e Sucessões. 8. ed. São Paulo: Almedina, 2020.

VERONESE, Josiane Petry. Os Direitos Fundamentais de Crianças e Adolescentes e a recepção da Doutrina da Proteção Integral pelo STJ. In: Revista Jurídica em Pauta. Vol. 1, n. 2, Bagé, 2019.

VÍTOR, PAULA TÁVORA. A carga do sustento e o pai social. In: Textos de Direito da Família para Francisco Pereira Coelho. Coimbra: Imprensa da Universidade de Coimbra, 2016.

\section{DÓRIS GHILARDI}

Doutora em Ciência Jurídica pela Univali-SC, com tese aprovada com distinção e louvor (2015); Mestra em Ciência Jurídica pela Univali -SC (2006); Formação e aperfeiçoamento pela Escola da Magistratura - ESMESC - Florianópolis - SC (2002); Professora adjunta da Universidade Federal de Santa Catarina - UFSC, na área de Direito Civil (graduação e pós-graduação stricto sensu); professora convidada permanente da Escola Superior da Advocacia de Santa Catarina - ESASC; Pesquisadora. Coordenadora do Grupo de Pesquisa Direito de Família e Sucessões em Perspectiva - GFAM/ UFSC/CNPQ, integrada à Rede REFAM. Coordenadora Científica do IBDFAM-SC. Diretora de Eventos do IBDCONT-SC.

Endereço profissional: Centro de Ciências Jurídicas, Campus Universitário Reitor João David Ferreira Lima, s/nº, Trindade, Florianópolis, SC, 88040-900, Brasil.

ORCID ID: https://orcid.org/0000-0002-2605-5785

E-MAIL: dorisghilardi@gmail.com

\section{DANIELA BRAGA PAIANO}

Professora Adjunto nível B da Universidade Estadual de Londrina (UEL), via concurso público desde 17 de maio de 2013, lotada no departamento de direito privado. Professora do Programa de 
Mestrado e Doutorado em Direito Negocial da UEL. Doutora em Direito pela Faculdade de Direito da Universidade de São Paulo (USP), 2016. Mestre pela Universidade de Marília (UNIMAR), 2006. Possui graduação em Direito pela Associação Educacional Toledo de Ensino (2001). Professora convidada na Pós Graduação da Universidade Estadual de Londrina. Advogada. Associada ao Instituto Brasileiro de Direito de Família - IBDFAM e ao International Society of Family Law - ISFL. Designada pela reitora da Universidade Estadual de Londrina a integrar o Conselho Editorial da Editora da UEL - EDUEL com segundo mandato até 27.08.2020. Endereço profissional: Universidade Estadual de Londrina, Estrutura Administrativa, Rodovia Celso Garcia Cid, Campus Universitário, Londrina, PR, 86.057-970, Brasil.

ORCID ID: https://orcid.org/0000-0002-8926-6555

E-MAIL: danielapaiano@hotmail.com

Recebido: 15/07/2021

Aceito: 30/09/2021

\section{(c) (i)}

Este trabalho está licenciado sob uma licença Creative Commons Attribution 4.0 International License.

Autores e autoras cedem à Revista Sequência direitos exclusivos de primeira publicação, ficando o trabalho licenciado sob a Creative Commons Attribution 4.0 International License. A licença autoriza que terceiros remixem, adaptem e ou criem a partir do trabalho publicado, indicando o crédito ao trabalho original e sua publicação inicial. Os autores têm permissão para assumir contratos adicionais em separado, com distribuição não exclusiva da versão publicada na Revista Sequência, indicando, de todo modo, a autoria e publicação inicial neste periódico. 